\title{
Effect of octreotide on fasting gall bladder emptying, antroduodenal motility, and motilin release in acromegaly
}

M F J Stolk, K J van Erpecum, H P F Koppeschaar, M Samsom, A J P M Smout, L M A Akkermans, T L Peeters, G P vanBerge-Henegouwen gall bladder volume is increased during octreotide treatment, which may show that interdigestive gall bladder emptying is also disturbed. $^{23}$ Several studies have shown that interdigestive gall bladder emptying is related to the migrating motor complex (MMC). ${ }^{4-7}$ The $M M C$ is a characteristic cyclic triphasic pattern of motor activity of the gastrointestinal tract. Phase III (strong contractions with maximal frequency) is probably responsible for the 'housekeeping' function of the MMC - that is, aboral propulsion of indigestible debris and prevention of small intestinal bacterial overgrowth. ${ }^{8}$ Phase III may originate in the antrum or in the duodenum. The start of phase III in the antrum is preceded by significant gall bladder emptying and motilin release whereas origination of phase III in the duodenum is not associated with these events. ${ }^{9} 10$ It is well known that somatostatin and octreotide have strong effects on the MMC in short term experiments. ${ }^{11-15}$ Single octreotide injections exclusively induce duodenal phase III like activity and suppress antral phase III. Moreover, motilin release is suppressed. ${ }^{13} 14$ However, the effects of longterm octreotide therapy on gastrointestinal motility are unknown. We hypothesised that in the fasting state, longterm octreotide administration is associated with an excess of duodenal phases III and gall bladder hypomotility. This study therefore examined the effects of two months of subcutaneous octreotide injection therapy on interdigestive gall bladder emptying, motilin release, and the MMC.

\section{Methods}

\section{Subjects}

Six patients with active acromegaly, requiring octreotide therapy, were enrolled in the study.

Keywords: gall bladder motility, gall stone formation, interdigestive manometry, migrating motor complex, octreotide.

Utrecht, the Netherlands
Necht, the

Gut Hormone Laboratory, Gasthuisberg, Belgium T L Peeters

Correspondence to: Correspondence to:
Dr M F J Stolk, Department of Gastroenterology, University Hospital Utrecht Postbox 85500, 3508 GA Utrecht, The Netherlands. Accepted for publication 30 August 1994
Subcutaneous injections with the somatostatin analogue octreotide (SMS201-995, Sandostatin) are an effective treatment for acromegaly, but lead to gall stone formation in $13-50 \%$ of cases during one year of therapy. ${ }^{1}$ The mechanism by which octreotide induces gall stones is not completely clear. Octreotide suppresses postprandial gall bladder contraction for several hours. ${ }^{2} 3$ In addition, fasting
TABLE I Characteristics of six acromegaly patients. IGF-I concentrations were measured before inclusion in the study and after two months of octreotide treatment

\begin{tabular}{lllcccc}
\hline & & & & \multicolumn{3}{c}{$I G F-I(\mathrm{ng} / \mathrm{ml})$} \\
\cline { 5 - 6 } Patient & Sex & $\begin{array}{c}\text { Age } \\
(y)\end{array}$ & $\begin{array}{c}\text { Body weight } \\
(\mathrm{kg})\end{array}$ & Before & During \\
\hline A & M & 42 & 88 & 799 & 789 \\
B & F & 32 & 71 & 1154 & 433 \\
C & F & 55 & 70 & 294 & 178 \\
D & M & 35 & 141 & 450 & 203 \\
E & M & 40 & 82 & 924 & 817 \\
F & M & 41 & 94 & 966 & 509 \\
\hline
\end{tabular}


All patients had typical clinical features of the acromegaly syndrome, high circulating growth hormone concentrations, which were not suppressed below $2 \mu \mathrm{g} / \mathrm{l}$ after an oral glucose load, and IGF-I (insulin like growth factor-I or somatomedin-C) plasma concentrations above the mean +2 SD for age. Table I shows patient characteristics. Ultrasound examination of the gall bladder, bile ducts, and liver was performed before the study and showed no stones, sludge or other abnormalities. None of the patients had previously had abdominal surgery. None of the patients were pregnant at the time of the study or receiving any treatment that could potentially interfere with gall bladder. motility. Body weight was stable during three months before the study. Ten healthy volunteers, matched for sex and age (male/female: $7 / 3$, age 38.3 (3.4) (mean (SD) years) served as controls for overnight antroduodenal manometry recordings. All patients and healthy volunteers gave written informed consent. The study protocol was approved by the ethical committee of our hospital.

\section{Protocol}

Patients and healthy volunteers fasted from $10 \mathrm{am}$. At $4 \mathrm{pm}$ a manometry catheter was introduced in the antrum and the duodenum and subjects went home with the catheter and a portable data recorder. At $7 \mathrm{pm}$ subjects had a standard meal (Stew, Iglo, Utrecht, the Netherlands; $1805 \mathrm{~kJ}: 27 \mathrm{~g}$ protein, $29 \mathrm{~g}$ carbohydrate, $23 \mathrm{~g}$ fat) and $200 \mathrm{ml}$ of water. After this meal, subjects fasted until the next morning. At 9 am patients returned fasted to the hospital and subsequently two consecutive cycles of the MMC were recorded. For healthy volunteers the study ended when they returned at $9 \mathrm{am}$. In acromegaly patients, gall bladder ultrasound images were obtained at five minute intervals and blood samples at 10 minute intervals, for two complete MMC cycles. The same procedure was repeated in acromegaly patients after two months of three daily subcutaneous injections of $100 \mu \mathrm{g}$ octreotide (Sandostatin, Sandoz AG, Basel, Switzerland). During the second test (that is, after introduction of the catheter at $4 \mathrm{pm}$ ), patients took octreotide injections $(100 \mu \mathrm{g}$ subcutaneously) at $11 \mathrm{pm}$ and at $7 \mathrm{am}$ and $3 \mathrm{pm}$ on the next day when measurements were obtained.

\section{Manometry}

Manometric recordings were obtained with a 6 channel solid state pressure sensor catheter (Gaeltec, Dunvegan, Scotland) with pressure sensors at $5,20,25,28,31$, and $34 \mathrm{~cm}$ from the tip. After introduction through the nose, the catheter was positioned under fluoroscopic control, with three to four sensors in the antrum ( $3 \mathrm{~cm}$ apart) and two to three sensors in the duodenum. The catheter was connected to a portable data recorder (Medical Measurement Systems, Enschede, the Netherlands). Sample frequency was $4 \mathrm{~Hz}$. The exact times of meals and octreotide injections were shown by pushing event buttons on the data recorder. After overnight recordings had been obtained, data were transferred from the data recorder to the main computer and stored. In acromegaly patients, the catheter was left in situ and connected to a polygraph (Model 7E, Grass Instrument Co, Quincy, MA, USA; paper speed $25 \mathrm{~mm} / \mathrm{min}$.) In this way, on line inspection of motility tracings was possible. Manometric recordings were continuously monitored by one investigator. During phase III like activity, duodenal contractions were never seen in the antral channels.

\section{Analysis of pressure recordings}

Manometric recordings were analysed visually. The most proximal duodenal recording site was used to identify phase I, II, and III. Phase I was defined as a period with no contractions, starting just after the end of phase III. Phase I ended and phase II started when contractions occurred at a rate of more than two per 10 minutes but less than two per minute in the antrum and less than 10 per minute in the duodenum and jejunum. Phase III was defined as rhythmic contractile activity, with a frequency of two to three contractions per minute in antrum during two minutes and 10-12 contractions per minute in the duodenum and the jejunum during three minutes. ${ }^{16} 17$ Phase III had to be propagated over at least three recording sites and had to be followed by phase I or quiescence. To be taken into account, antral phase III had to be propagated to the duodenum. ${ }^{16}$ In all cases, antral phase III was followed by duodenal and jejunal phase III. All activity fronts that started in the duodenum, were propagated over at least two recording sites. The site of origin of each phase III was noted. Total cycle length was calculated from the end of phase III in proximal duodenum to the end of next phase III. To compare motility patterns of healthy volunteers and acromegaly patients properly, the two additional MMC cycles, measured in acromegaly patients, were not included in the analysis. The length of the postprandial period was defined as the time from meal ingestion to the occurrence of the first phase III.

A quantitative description of phase III was obtained by multiplying the incidence of contractions with the mean amplitude of contractions during phase III. ${ }^{14}$

\section{Gall bladder volume measurements}

When the patient returned to the hospital in the morning, gall bladder volume was measured by real time ultrasonography (SDR 1500, Philips Ultrasound, Santa Ana, CA, USA: $5.0 \mathrm{MHz}$ transducer). Sagittal and transverse scans of the gall bladder at its largest dimensions were obtained. Gall bladder images were made every five minutes during two complete MMC cycles. These images were stored on videotape and processed by a 
TABLE II Parameters of interdigestive antroduodenal motility in healthy subjects $(n=10)$ and acromegaly patients $(n=6)$ before and after two months of octreotide treatment (mean (SEM)

\begin{tabular}{|c|c|c|c|}
\hline Parameter & $\begin{array}{l}\text { Healthy } \\
\text { subjects }\end{array}$ & $\begin{array}{l}\text { Acromegaly patients } \\
\text { before octreotide }\end{array}$ & $\begin{array}{l}\text { Acromegaly patients } \\
\text { during octreotide }\end{array}$ \\
\hline Recording time $(\mathrm{h})$ & $16 \cdot 3(0 \cdot 4)$ & $16.4(0.9)$ & $15.8(0.9)$ \\
\hline Length of postprandial period $(\mathrm{h})$ & $8.0(0.6)$ & $6 \cdot 4(0.8)$ & $3 \cdot 1(0 \cdot 6)^{\star}$ \\
\hline No of MMC cycles & $3.6(0.5)$ & $4 \cdot 3(0.9)$ & $8 \cdot 0(1 \cdot 3)^{\star}$ \\
\hline MMC cycles $/ \mathrm{h}$ & $0.74(0.06)$ & $0.66(0.08)$ & $0.84(0.08)$ \\
\hline MMC cycle length (min) & $85 \cdot 7(7 \cdot 8)$ & $99 \cdot 6(13 \cdot 3)$ & $76.0(9 \cdot 8)^{\star}$ \\
\hline Phase I (min) & $46 \cdot 6(5 \cdot 7)$ & $61.0(10.0)$ & $48.8(3.9)$ \\
\hline Phase II (min) & $33 \cdot 3(5 \cdot 4)$ & $31.5(11 \cdot 2)$ & $20 \cdot 0(7 \cdot 8)$ \\
\hline Phase III (min) & $5 \cdot 8(0.5)$ & $7 \cdot 2(1 \cdot 6)$ & $7 \cdot 2(0 \cdot 4)$ \\
\hline $\begin{array}{l}\text { Antral/duodenal phase III no } \\
\text { Spontaneous phase III }\end{array}$ & $14 / 22$ & $9 / 17$ & $1 / 47^{\star}$ \\
\hline \multirow{3}{*}{$\begin{array}{l}\text { Phase III contraction incidence } \\
\text { (contraction } / \mathrm{min}) \\
\text { Phase III contraction } \\
\text { amplitude }(\mathrm{kPa}) \\
\text { incidence } \times \text { amplitude } \\
\text { (contraction } / \mathrm{min} \times \mathrm{kPa})\end{array}$} & $10 \cdot 7(0 \cdot 3)$ & $10.5(0.4)$ & $9.9(0.4)$ \\
\hline & $3.9(0 \cdot 2)$ & $4 \cdot 4(0 \cdot 2)$ & $4 \cdot 0(0 \cdot 1)$ \\
\hline & $41 \cdot 4(2 \cdot 6)$ & $46 \cdot 6(3 \cdot 4)$ & $40 \cdot 0(2 \cdot 3)$ \\
\hline Octreotide induced phase III & & & \\
\hline $\begin{array}{l}\text { Phase III contraction incidence } \\
\text { (contraction } / \mathrm{min} \text { ) }\end{array}$ & NS & NS & $10 \cdot 6(0 \cdot 4)$ \\
\hline \multirow{2}{*}{$\begin{array}{l}\text { Phase III contraction } \\
\text { amplitude }(\mathrm{kPa}) \\
\text { incidence } \times \text { amplitude } \\
\quad(\text { contraction } / \mathrm{min} \times \mathrm{kPa}\end{array}$} & NS & NS & $4 \cdot 7(0 \cdot 3) \dagger$ \\
\hline & NS & NS & $49 \cdot 9(4 \cdot 7)$ \\
\hline
\end{tabular}

$\star=$ significantly different from healthy subjects and before octreotide treatment $(p<0 \cdot 05)$. $\dagger=$ significantly different from spontaneous phases III during octreotide treatment and from healthy subjects $(\mathrm{p}<0 \cdot 05)$.

\section{Results}

\section{Motility recordings}

Table II gives the results of the ambulatory antroduodenal recordings in acromegaly patients and healthy controls. No significant differences for interdigestive motility parameters were found between healthy volunteers and untreated acromegaly patients. The length of the MMC cycle decreased from $99.6(13.3)$ $\min$ to $76.0(9.8)$ min $(\mathrm{p}<0.05)$ during octreotide treatment. Although the length of phase I and II decreased during octreotide treatment with $20 \%$ and $37 \%$ respectively, differences did not reach statistical significance. The number of MMC cycles increased from $4.3(0.9)$ to $8.0(1.3)$ during octreotide treatment $(\mathrm{p}<0.05$; Fig 1$)$.

In the untreated acromegaly patients, phase III originated in nine of $26 \mathrm{MMC}$ cycles in the antrum, whereas only one of 48 of phase III like activity originated in the antrum during octreotide treatment $(p<0.05)$. Subcutaneous injection of $100 \mu \mathrm{g}$ octreotide invariably induced a duodenal phase III like activity after $5.9(0.4) \mathrm{min}$.

The amplitude of duodenal phase III like

MS-DOS computer, using a video grabber and processing software (IBAS, Kontron, Munich, Germany). Gall bladder volume was calculated with the sum of cylinders method. ${ }^{18}$

\section{Plasma hormone analysis}

An in dwelling cannula in the antecubital vein was used to take blood samples at 10 minute intervals for two complete MMC cycles. Blood was collected in ice chilled tubes, preloaded with $50 \mu \mathrm{l}$ aprotinin (Trasylol, Bayer, Leverkusen, Germany) per ml blood. Plasma was stored at $-20^{\circ} \mathrm{C}$ until analysis. Plasma motilin concentrations were measured by a sensitive and specific radioimmunoassay, without knowledge of the motility recordings, as described previously. ${ }^{19}$ During the second test, every 30 minutes, blood samples were taken for octreotide concentrations. Plasma octreotide concentrations (in $\mathrm{pg} / \mathrm{ml}$ ) were assessed by radioimmunoassay (Sandoz, Basle, Switzerland).

\section{Statistical analysis}

Changes of gall bladder volumes and motilin concentrations were examined by repeated measures analysis of variance. When a significant difference was detected, results were further compared for contrasts by Fisher's LSD test. Parameters of fasting antroduodenal motility were compared between healthy subjects and acromegaly patients with the Mann-Whitney test. Comparisons before and during octreotide treatment of patients with acromegaly were made with Wilcoxon's test. All values were given as mean (SEM). Statistical significance was defined as a two tailed probability of less than $0 \cdot 05 .{ }^{20}$ To avoid interference from intrasubject and intersubject variation of MMC cycle length, each total cycle length was set at $100 \%$ and divided into 10 segments of $10 \%$. activity directly after octreotide injection (4.7 $(0 \cdot 3) \mathrm{kPa})$ was significantly higher compared with the spontaneous phases III during octreotide treatment $(4.0(0 \cdot 1) \mathrm{kPa})$ or with phases III in healthy volunteers $(3.9(0.2) \mathrm{kPa}$; $\mathrm{p}<0 \cdot 05)$. All other phase III like activities during octreotide treatment were comparable with spontaneous phases III in healthy subjects and untreated acromegaly patients (Table II).

In acromegaly patients, octreotide treatment considerably reduced the duration of the postprandial period after the evening meal from 6.4 $(0 \cdot 8)$ h to $3 \cdot 1(0.6) h(p<0.05)$.

\section{Gall bladder volumes}

Gall bladder volume was monitored during 12 MMC cycles in the untreated state. Four MMC cycles had phase III starting in the antrum and eight at the level of the duodenum. Before octreotide treatment, a significant decrease of gall bladder volume during the cycle was only seen in MMC cycles with antral phase III and not in MMC cycles with phase III starting at the level of the duodenum (Fig 2). Minimum gall bladder volume was reached between the 81 st and 90th percentile of the MMC cycle, just before phase III. Maximum decrease of gall bladder volume in MMC cycles with antral phase III (39.9 $(4 \cdot 0) \%$ ) was significantly larger compared with MMC cycles with duodenal phase III $(17 \cdot 4$ $(5 \cdot 8) \% ; \mathrm{p}<0.05)$.

During octreotide treatment, gall bladder volume was monitored during $11 \mathrm{MMC}$ cycles in which all phases III started at the level of the duodenum. No significant gall bladder volume fluctuations were seen during the MMC cycle. Maximum decrease of gall bladder volume was $20.3(3 \cdot 7) \%$ during octreotide treatment, which was comparable with maximum gall bladder emptying in MMC cycles with duodenal phase III in the untreated state. 

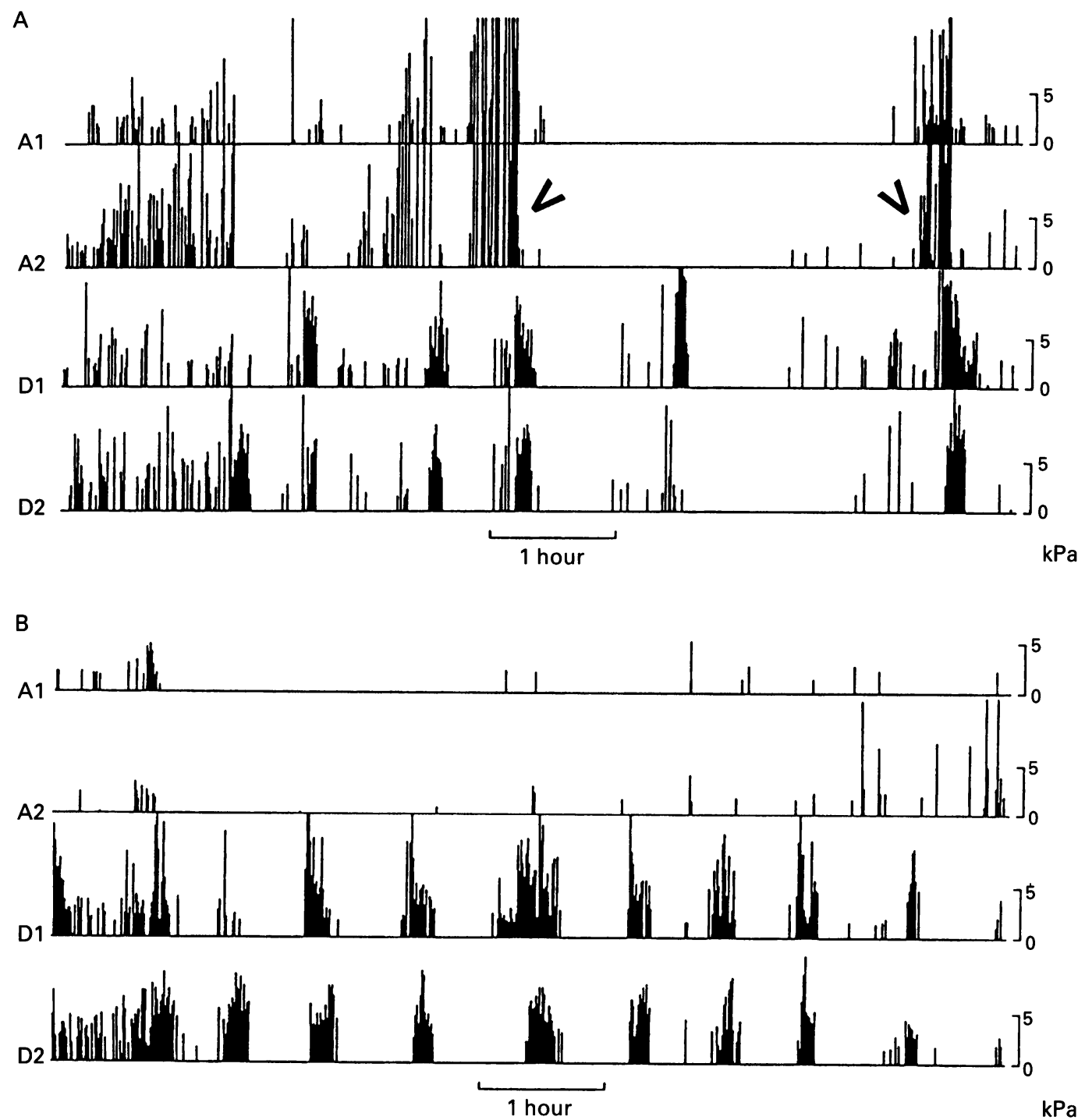

Figure 1: Overnight interdigestive antroduodenal motility before $(A)$ and during (B) two months of octreotide treatment. Before octreotide treatment two antral phases III are seen (arrows). During octreotide treatment the number of MMC cycles increased. During octreotide treatment, all phase III like activity originated in the duodenum (A1, A2 antral channels, D1, D2 duodenal channels).

Mean fasting gall bladder volume before octreotide treatment was $40.9(9 \cdot 1) \mathrm{ml}$ and increased to $68.0(14.8) \mathrm{ml}(\mathrm{p}<0.05)$ after two months of octreotide treatment.

\section{Plasma motilin concentration}

In the untreated state, only MMC cycles with antral phase III showed a significant increase of motilin concentrations at the end of phase II, just before phase III (Fig 3). In MMC cycles with duodenal phase III, no significant change of motilin concentrations was seen. During octreotide treatment, motilin concentrations were suppressed to $49.0 \%$ of the lowest concentration in the untreated state $(p<0.05)$ and showed no significant fluctuation during the MMC cycle (Fig 3 ). In one patient, plasma motilin concentrations were below the detection limit of the assay $(24 \mathrm{pg} / \mathrm{ml})$ during two MMC cycles.

\section{Plasma octreotide concentration}

Plasma octreotide concentrations at the start of the first MMC cycle were $2242.2(369.5)$ $\mathrm{pg} / \mathrm{ml}$ and decreased to $1314.5(231.9) \mathrm{pg} / \mathrm{ml}$ $(\mathrm{p}<0.05)$ at the end of the cycle. In the next MMC cycle octreotide plasma concentration decreased further from $1204.8(242 \cdot 7) \mathrm{pg} / \mathrm{ml}$ to $806.5(265 \cdot 7) \mathrm{pg} / \mathrm{ml}(\mathrm{p}<0.05)$. Octreotide concentrations showed that patients complied to the study protocol. In all patients significant negative correlations between octreotide and motilin plasma concentrations were seen $(r=-0.53(0.1), \mathrm{p}<0.05)$.

\section{Discussion}

Three daily subcutaneous octreotide injections are commonly used for the treatment of acromegaly. However, a high incidence of gall stones (between 13-50\%) after one year of treatment was reported. ${ }^{1}$ Recently, several mechanisms have been elucidated, which may participate in the pathogenesis of gall stones in these patients.

Firstly, octreotide reduces the secretion of the bicarbonate rich fraction of the bile, increases biliary cholesterol saturation, ${ }^{21}$ and increases the fraction of the hydrophobic bile acid deoxycholate. ${ }^{22}$ Deoxycholate may participate in the pathogenesis of cholesterol gall stones. ${ }^{23}$ 


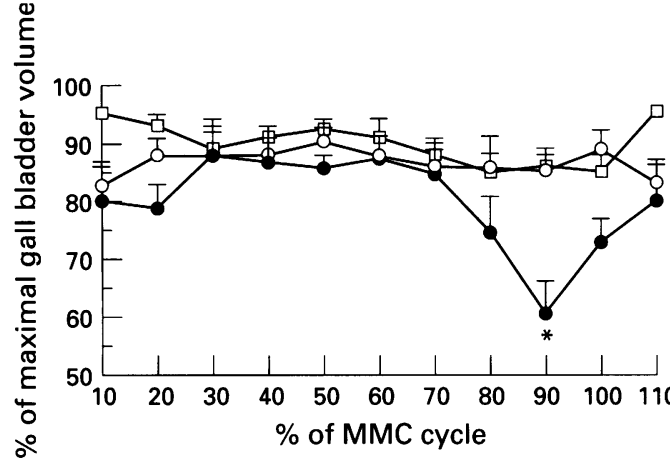

Figure 2: Relation between interdigestive gall bladder emptying and the $M M C$ cycle. Gall bladder emptying is expressed as percentage of maximal gall bladder volume during the cycle. Percentiles denote fraction of elapsed total cycle length. Closed circles show cycles with phase III starting in antrum and open circles show cycles with phase III starting in duodenum before octreotide treatment. Open squares show cycles with phase III like activity starting in the duodenum during octreotide treatment. Only antral phase III is preceded by significant decrease of gall bladder volume. ${ }^{\star}=$ significantly different from $p 10$ to $\mathrm{p} 70$ ).

Secondly, acute octreotide administration reduces postprandial gall bladder emptying probably through suppression of cholecystokinin release. ${ }^{23}$ In addition, somatostatin has been shown to suppress acetylcholine release. ${ }^{24}$ In several studies increased postprandial residual and fasting gall bladder volumes were seen. ${ }^{23}$ Impaired gall bladder emptying may provide time for cholesterol crystal precipitation from supersaturated bile and subsequent gall stone formation. Microscopic examination of duodenal bile from acromegaly patients treated with octreotide showed cholesterol crystals in $64 \%$ of patients. ${ }^{25}$

This study showed for the first time that during two months octreotide treatment interdigestive gall bladder emptying is also severely impaired. Figure 2 showed only small gall bladder volume fluctuations during octreotide treatment, which were not statistically significant, although a type II error cannot be excluded. Impaired interdigestive gall bladder emptying might explain increased fasting gall bladder volume during octreotide treatment. In addition, octreotide increases basal pressure in the sphincter of Oddi, which may further

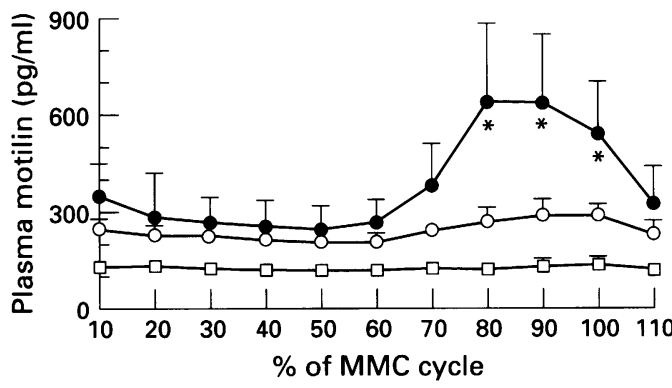

Figure 3: Relation between interdigestive motilin release and MMC cycle. Percentiles denote fraction of elapsed total cycle length. Closed circles show cycles with phase III starting in antrum. A significant motilin peak is seen at the end of phase II, before phase III starts in the antrum $\left(^{\star}=\right.$ significantly different from $p 10$ to $\left.p 70\right)$. Open circles show cycles with phase III starting in duodenum before octreotide treatment. Open squares show cycles with phase III like activity starting in duodenum during octreotide treatment. contribute to increased fasting gall bladder volume. ${ }^{26}$ In healthy humans, gall bladder bile concentration is maximal during the night with transient biliary cholesterol supersaturation. ${ }^{27}$ Reduced bile secretion, as occurs during octreotide treatment, has also been shown to be associated with increased bile lithogenicity. ${ }^{28}$ Periodic interdigestive gall bladder emptying with subsequent influx of fresh, dilute hepatic bile, however, may prevent precipitation of cholesterol crystals. Interdigestive gall bladder bile stasis in patients receiving longterm octreotide treatment might lead to progressive concentration of gall bladder bile, which promotes precipitation of cholesterol crystals. This might contribute to the high incidence of cholesterol gall stones.

Effects of octreotide on the MMC of the gastrointestinal tract may be relevant for the effects on interdigestive gall bladder motility. The gall bladder empties periodically in the fasting state, in coordination with the MMC. It was recently shown that interdigestive gall bladder emptying is particularly associated with the subsequent occurrence of antral phase III and a plasma motilin peak. ${ }^{10}{ }^{29}$ In this study similar findings were made. In untreated acromegaly patients, antral phase III was preceded by significant plasma motilin peaks and gall bladder emptying, which was not the case for phase III starting in the duodenum. After two months of octreotide treatment antral phase III was virtually abolished, no significant gall bladder volume or plasma motilin fluctuation were found, and fasting gall bladder volume was increased. After short term infusion of somatostatin-14 in humans, a significant gall bladder volume reduction was still seen just before phase III like activity. ${ }^{30}$ This conflicting result may be explained by pharmacokinetic differences between somatostatin-14 and octreotide and by the length of the treatment period.

As Table II shows, two months of treatment with octreotide significantly increased the number of MMC cycles and decreased MMC cycle length. These findings are in agreement with previous reports on the effects of somatostatin and octreotide in short term experiments. ${ }^{11} 1230$

In contrast with previous studies, in which a much more pronounced reduction of phase II was seen in our study octreotide treatment did not significantly decrease the length of phase II. ${ }^{11} 12$ These studies, however, were short lasting experiments carried out in dogs or with somatostatin, while we studied the effects of two months of octreotide treatment in humans for about 16 hours. Therefore different experimental set up, drug or species might explain differences although a type II error cannot be excluded in this study. Moreover, adaptation to effects of octreotide may have occurred during two months of octreotide treatment.

Several mechanisms can be proposed by which octreotide may interfere with normal antroduodenal fasting motility.

Firstly, octreotide may have a direct, local effect on the small intestine. Intraarterial 
somatostatin infusion of intestinal segments in dogs suggested that somatostatin induces phase III like activity through a local mechanism. ${ }^{31}$

Secondly, octreotide may act through suppression of motilin release. Antral phase III can only be induced by motilin or motilin agonists like erythromycin. ${ }^{32}$ Decreased motilin concentrations during octreotide treatment, as found in our study have also been reported previously. ${ }^{1314}$ This might explain the virtual absence of antral phase III in this study.

Thirdly, octreotide may act through the suppression of interdigestive cyclic bile flow. It has been shown that periodic delivery of bile to the small intestine is associated with cyclic motilin release. ${ }^{103334}$ As interdigestive gall bladder emptying during octreotide treatment is suppressed, no motilin fluctuations might be expected. This suggests that in the small bowel other, only partially motilin dependent or even motilin independent mechanisms, similar to direct octreotide effects as mentioned above, might be responsible for induction of duodenal phase III like activity.

From this study, however, no conclusion can be drawn on the exact mechanism by which octreotide affects the MMC.

In conclusion, this study shows for the first time that two months of subcutaneous octreotide injections suppress interdigestive gall bladder emptying, increase fasting gall bladder volume, suppress motilin concentrations, reduce the occurrence of antral phase III, and increase the incidence of duodenal phase III like activity. These factors may contribute to the increased incidence of gall stones in patients receiving longterm octreotide therapy.

The authors thank $\operatorname{Dr} M$ Terlou for calculation of gall bladder volumes, $R$ Meijer for ultrasonographic assistance, Dr J van volumes, $R$ Meijer for ultrasonographic assistance, Dr J van Bree, Sandoz Switzerland, for octreotide measurements, and
Professor dr M Y Ke, Peking United Medical College Hospital, Professor dr M Y Ke, Peking United Medical College Hospital, China, for technical assistance. This study was supported by the Netherlands Foundation for Medical Research (NWO-MW)
grant no 900-522-106 and by the Royal Netherlands Academy of Arts and Sciences.

Part of this work has been presented as poster at the 2nd United European Gastroenterology Week in Barcelona 1993.

1 Dowling RH, Hussaini SH, Murphy GM, Wass JAH Gallstones during octreotide therapy. Digestion 1993;54 (suppl 1): 107-20.

2 Liessum van PA, Hopman WPM, Pieters GFFM, Jansen JBMJ, Smals AGH, Rosenbusch G, et al. Postprandial gallbladder motility during long term treatment with the gallbladder motility during long term treatment with the long-acting somatostatin analog SMS $201-995$ in 557-62.

3 Stolk MFJ, van Erpecum KJ, Koppeschaar HPF, de Bruin WI, Jansen JBMJ, Lamers CBHW, et al. Postprandial gal bladder motility and hormone release during intermittent and continuous subcutaneous octreotide treatment in acromegaly. Gut 1993; 34: 808-13.

4 Itoh Z, Takahashi I. Periodic contractions of the canine gallbladder during the interdigestive state. Am $\mathcal{F}$ Physiol 1981; 240: G183-9.

5 Kraglund K, Hjermind J, Jensen FT, Stodkilde-Jorgensen H, Oster-Jorgensen E, Pedersen SA. Gallbladder emptying and gastrointestinal cyclic motor activity in humans. Scand $\mathcal{F}$ Gastroenterol 1984; 19: 990-4.

6 Marzio L, Neri M, Capone F, Di Felice F, De Angelis C, Mezzetti A, et al. Gallbladder contraction and its relationMezzetti A, et al. Gallbladder contraction and its relationship to interdigestive duodenal motor activity in

7 Qvist N, Oster-Jorgensen E, Rasmussen L, Kraglund K, Pedersen SA. The relationship between gallbladder dynamics and the migrating motor complex in fasting healthy subjects. Scand $\mathcal{F}$ Gastroenterol $1988 ; 23: 562-6$.
8 Vantrappen G, Janssens J, Hellemans J, Ghoos Y. The interdigestive motor complex of normal subjects and patients with bacterial overgrowth of the small intestine. $₹$ Clin Invest 1977; 59: 1158-66.

9 Bormans V, Peeters TL, Janssens J, Pearce D, Vandeweerd $M$, Vantrappen $G$. In man, only activity fronts that originate in the stomach correlate with motilin peaks. Scand $\mathcal{f}$ Gastroenterol 1987; 22: 781-4.

10 Stolk MFJ, van Erpecum KJ, Smout AJPM, Akkermans LMA, Jansen JBMJ, Lamers CBHW, et al. Motor cycles with phase III in antrum are associated with high motilin levels and prolonged gallbladder emptying. Am $f$ Physiol 1993; 264: G596-600.

11 Peeters TL, Janssens J, Vantrappen GR. Somatostatin and the interdigestive migrating motor complex in man Regul Pept 1983; 5: 209-17.

12 Peeters TL, Romanski KW, Janssens J, Vantrappen G. Effect of the long-acting somatostatin analogue SMS 201995 on small-intestinal interdigestive motility in the dog. Scand $\mathcal{F}$ Gastroenterol 1988; 23: 769-74.

13 Poitras P, Steinbach JH, VanDeventer G, Code CF, Walsh $\mathrm{JH}$. Motilin-independent ectopic fronts of the interdigestive myoelectric complex in dogs. Am F Physiol 1980; 239: G215-20.

14 Soudah HC, Hasler WL, Owyang C. Effect of octreotide on intestinal motility and bacterial overgrowth in scleroderma. $N$ Engl F Med 1991; 325: 1461-7.

15 Thor P, Krol R, Konturek SJ, Coy DH, Schally AV. Effect of somatostatin on myoelectrical activity of the smal bowel. Am $\mathcal{F}$ Physiol 1978; 235: E249-54.

16 Kellow JE, Borody TJ, Phillips SF, Tucker RL, Haddad AC. Human interdigestive motility: variations in pattern from esophagus to colon. Gastroenterology 1986;91: 386-95.

17 Rees WDW, Malagelada J-R, Miller LJ, Go VLW. Human interdigestive and postprandial gastrointestinal motor and gastrointestinal hormone patterns. Dig Dis Sci 1982; 27: gastroin.

18 Everson GT, Braverman DZ, Johnson ML, Kern F Jr. A critical evaluation of real-time ultrasonography for the study of gallbladder volume

19 Peeters TL, Vantrappen G, Janssens J. Fasting plasma motilin levels are related to the interdigestive motility complex. Gastroenterology 1980; 79: 716-9.

20 Armitage P, Berry G. Statistical methods in medical research 2nd ed. Oxford: Blackwell Scientific, 1987: 296

21 Cucchiaro G, Branum GD, O'Dorisio T, Meyers WC. Effect of somatostatin and its analogue sandostatin on biliary lipid composition. Gastroenterology 1990; 98: on biliar.

22 Hussaini SH, Murphy GM, Kennedy C, Wass JAH, Dowling RH. Chronic octreotide treatment of acromegaly induces changes in gallbladder bile composition which predispose to gallstones. Gastroenterology 1993; 104: predis.

23 Marcus SN, Heaton KW. Deoxycholic acid and the pathogenesis of gall stones. Gut 1988; 29: 522-33.

24 Guillemin R. Somatostatin inhibits the release of acetylcholine induced electrically in the myenteric plexus. Endocrinology 1976; 99: 1653-4.

25 Buscail LE, Puel-Bousquet C, Harris AG, Tauber JP, Escourrou JR, Delveaux MM, Vaysse NM, Bayard F, Robet A. Effets sur la lithogenese biliaire du traitement au long cours par octreotide (SMS 201-995) chez des patients acromegales. Gastroenterol Clin Biol 1991; 15: patients

26 Binmoeller KF, Dumas R, Harris AG, Delmont JP. Effects of somatostatin analog octreotide on human sphincter of Oddi. Dig Dis Sci 1992; 37: 773-7.

27 Holzbach RT, Marsh M, Olszewski M, Holan K. Cholesterol solubility in bile. Evidence that supersaturated bile is frequent in healthy man. $\mathcal{f}$ Clin Invest 1973; 52: 1467-79.

28 Northfield TC, Hofmann AF. Biliary lipid output during three meals and an overnight fast. I. Relationship to bile acid pool size and cholesterol saturation of bile in gallstone and control subjects. Gut 1975;16: 1-11.

29 Ura K, Sarna SK, Condon RE. Antral control of gallbladder cyclic motor activity in the fasting state. Gastroenterology 1992; 102: 295-302.

30 Neri M, Cuccurullo F, Marzio L. Effect of somatostatin on gallbladder volume and small intestinal motor activity in humans. Gastroenterology 1990; 98: 316-21.

31 Hostein J, Janssens J, Vantrappen G, Peeters TL, Vanderweerd M, Leman G. Somatostatin induces ectopic activity fronts of the migrating motor complex via a local intestinal mechanism. Gastroenterology 1984; 87: 1004-8.

32 Peeters, TL, Matthijs G, Depoortere I, Cachet T, Hoogmartens J, Vantrappen G. Erythromycin is a motilin receptor agonist. Am $\mathcal{F}$ Physiol 1989; 257: G470-4.

33 Nilsson BI, Svenberg T, Tollstrom T, Hellstrom PM, Samuelson K, Schnell P-O. Relationship between interSamuelson K, Schnell P-O. Relationship between inter-
digestive gallbladder emptying, plasma motilin and digestive gallbladder emptying, plasma motilin and
migrating motor complex in man. Acta Physiol Scand 1990; 139: 55-61.

34 Svenberg T, Christofides ND, Fitzpatrick ML, Areola-Oritz F, Bloom SR, Welbourn RB. Interdigestive biliary output in man: relationship to fluctuations in plasma motilin an effect of atropine. Gut 1982; 23: 1024-8. 